Interfaces between medical specialties

\title{
Thyroid disease in pregnancy
}

\author{
W M Drake, D F Wood
}

\section{Summary}

This review article provides a broad overview of thyroid disease and pregnancy.

\begin{tabular}{|l|}
\hline Changes in thyroid physiology \\
with pregnancy \\
\hline serum $T B G$ increases \\
total $\mathrm{T}_{4}$ and $\mathrm{T}_{3}$ rise as a result \\
greater renal clearance of iodide \\
free $\mathrm{T}_{4}$ and $\mathrm{TSH}$ are the best \\
indicators of thyroid function
\end{tabular}

Box 1
Thyroid disease is common in the UK population and, of those affected, a significant proportion are women of reproductive age. Hence, it is not uncommon for physicians, obstetricians and paediatricians to encounter thyroid disease in the context of infertility clinics, pregnancy, the post-partum period and in the neonate. Following successful implantation of the blastocyst, significant changes in thyroid physiology occur in order to guarantee maternal and foetal euthyroidism through to term. Knowledge of these changes is essential if thyroid function tests are to be interpreted accurately and correct decisions made about patient management. Abnormalities of thyroid function may have important effects on mother and foetus, due either to the biochemical disturbance (hyperor hypothyroxinaemia) or because of placental transfer of the antibodies that may underlie that disturbance.

\section{Thyroid physiology during pregnancy}

\section{MATERNAL}

Interpretation of thyroid function tests during pregnancy is made difficult for several reasons. Circulating blood volume rises by around $40 \%$, with a consequent relative dilution of serum proteins. Despite this dilutional effect, serum thyroxine-binding globulin (TBG) levels rise in pregnancy due to oestrogen-mediated increases in hepatic synthesis and greater sialylation, with consequent decreased hepatic clearance, of TBG. ${ }^{1}$ High levels of deiodinases types II and III are found in placental tissue, such that in pregnancy there is, proportionally, greater production of biologically inactive reverse triiodothyronine $\left(\mathrm{rT}_{3}\right)$ than in the non-pregnant state. ${ }^{2}$ Taking into account all these factors, most people regard serum free thyroxine $\left(\mathrm{T}_{4}\right)$ and thyroxinestimulating hormone (TSH) as the most reliable indicators of thyroid function during pregnancy.

Normal pregnancy is associated with a rise in glomerular filtration rate, such that renal clearance of iodide increases. This increased loss may be sufficient to decompensate women with marginal iodine deficiency, leading to goitre. ${ }^{45}$

\section{FOETAL}

The developing pituitary-thyroid axis is sufficiently mature to be functioning towards the end of the first trimester, with foetal-derived $\mathrm{T}_{4}$ detectable in blood from around 10 weeks gestation. ${ }^{2}$ However, significant concentrations of $T_{4}$ and $\mathrm{T}_{3}$ are detectable in the blood of neonates unable to synthesise thyroid hormone due to congenital organification defects, suggesting that placental transfer of thyroid hormone also occurs. ${ }^{5}$ The physiological relevance of this transfer of thyroid hormone in terms of foetal development is not certain, although the syndrome of cretinism (see below) that occurs with maternal iodine deficiency would suggest it may be important in the early development of the central nervous system.

\section{Hypothyroidism in pregnancy}

It is unusual for women with untreated hypothyroidism to conceive, given the high incidence of anovulatory cycles associated with this condition. Where it occurs, the diagnosis may often be delayed as many of the symptoms of hypothyroidism (tiredness, irritability, poor concentration and paraesthesiae due to carpal tunnel syndrome) are also features of normal pregnancy, such that the level of clinical suspicion may be low. Biochemically, serum TSH is the most reliable indicator of genuine hypothyroidism, as total $\mathrm{T}_{4}$ may be within the reference range due to pregnancy-induced increases in TBG levels. A more usual problem for the endocrinologist is the adjustment of thyroxine replacement treatment during pregnancy. Most cases of pre-existing and pre-treated hypothyroidism during pregnancy are due to autoimmune thyroid failure, but some women may be hypothyroid consequent to treatment with radio-iodine or surgery for previous thyrotoxicosis. Although there is some evidence that titres of antithyroid antibodies fall during pregnancy (in keeping with the notion of preg- 


\section{Hypothyroidism during pregnancy \\ - most cases diagnosed and treated before conception \\ - generally due to autoimmune (Hashimoto's) thyroiditis \\ - TSH the best indicator of adequate thyroid replacement}

Box 2 nancy being an 'immunosuppressed' state) ${ }^{6}$ it is not infrequent for the requirement for thyroxine replacement to rise progressively during pregnancy by $25-50 \% .^{7}$ Most authorities agree that an ideal replacement dose of thyroxine in pregnancy should keep the free $\mathrm{T}_{4}$ in the upper part and TSH in the lower part of the respective reference ranges.

FOETAL OUTCOME AND DEVELOPMENT

Given that almost all women with hypothyroidism are already established on thyroxine replacement treatment before pregnancy, it is (or should be) unusual for maternal hypothyroxinaemia to affect foetal development. Untreated hypothyroidism in pregnancy is associated with an increased perinatal mortality (stillbirths and neonatal deaths) ${ }^{8}$ and congenital malformations. In cases of severe iodine deficiency, maternal and foetal hypothyroidism combine to produce the classical 'cretin' with mental retardation, deafness and spastic diplegia. Screening of newborn infants with the Guthrie test ensures that neonatal hypothyroidism from any cause (dysgenesis, organification defects or iodine deficiency) should never go untreated.

\section{Thyrotoxicosis and pregnancy}

Unlike hypothyroidism, it is not uncommon for women with thyrotoxicosis to conceive. The diagnosis and management of pregnant women with thyrotoxicosis is therefore a significant and challenging clinical problem, particularly as many of the symptoms and signs of hyperthyroidism are present in women with uncomplicated pregnancies.

\section{PREVALENCE AND AETIOLOGY}

Newly diagnosed thyrotoxicosis occurs in approximately $0.05 \%$ of pregnancies, ${ }^{9}$ although there are a number women in whom the diagnosis is made prior to conception, such that the overall prevalence of thyrotoxicosis in pregnancy is $0.2 \% .^{10}$ Almost all cases are due to Graves' disease, although trophoblastic diseases (hydatidiform mole and choriocarcinoma) represent an important minority and will be discussed in a separate section. As with other autoimmune diseases, the clinical course of Graves' disease is often improved by pregnancy. Titres of microsomal antithyroid antibodies fall towards term, in keeping with the concept of pregnancy as an 'immunosuppressed' state. In contrast, Graves' disease often worsens following parturition, in association with rising antibody titres. This, and other aspects of post-partum thyroid disease, are discussed below.

\section{EFFECTS OF THYROTOXICOSIS IN PREGNANCY}

Data on the effect of undiagnosed thyrotoxicosis at the time of conception on subsequent foetal outcome are difficult to interpret, as such studies are, by definition, retrospective. Furthermore, once the diagnosis has been made it is unethical to withhold antithyroid medication, making controlled studies on the effect of thyrotoxicosis on foetal outcome similarly difficult. Despite these shortcomings there are data to suggest that uncontrolled thyrotoxicosis during pregnancy is associated with increased foetal loss and babies born small for gestational age, ${ }^{9}$ although the mechanisms for this are not clear.

\section{DIAGNOSIS}

The diagnosis of thyrotoxicosis in pregnancy relies largely on laboratory investigations, as many of the clinical features of hyperthyroidism (heat intolerance, warm peripheries and tachycardia) are present in normal pregnancy. As detailed above, total $T_{4}$ and $T_{3}$ are elevated in pregnancy due to increases in TBG, such that measurements of both free $\mathrm{T}_{4}$ and $\mathrm{TSH}$ are essential for accurate diagnosis. Where there is diagnostic doubt it is reasonable to repeat the tests after two to three weeks before instituting therapy.

HYPEREMESIS, $\beta$-hCG AND THYROTOXICOSIS (GESTATIONAL THYROTOXICOSIS)

Interest in the role of $\beta$-human chorionic gonadotropin ( $\beta$-hCG) as a thyroid stimulator arose with the observation that thyrotoxicosis was occasionally associated with trophoblastic diseases such as hydatidiform mole and choriocarcinoma. ${ }^{11}$ The structural homology that exists between TSH and hCG led to the postulate that hCG cross-reacts with the TSH receptor, leading to thyroid stimulation and release of thyroid hormone.

The relationship between hCG, hyperthyroxinaemia and vomiting in non-molar pregnancies is less clear. Women with Graves' thyrotoxicosis in pregnancy often present with vomiting but, conversely, many women with hyperemesis gravidarum (defined by vomiting sufficiently severe to cause $>3 \%$ loss of body weight with ketonuria and electrolyte disturbances) often have abnormali- 


\section{Case history}

A 26-year-old Bengali woman was admitted to hospital 8 weeks into her third pregnancy with suspected hyperemesis gravidarum. Both previous pregnancies had been uneventful and there was no history of thyroid disease. Physical examination was unremarkable. In particular, she was clinically euthyroid with no goitre. Routine haematological and biochemical investigations, including thyroid function tests, were normal. After 3 days of intravenous fluids and anti-emetics she was discharged, feeling well. A week later she was re-admitted with further vomiting. Clinical examination was again unremarkable. Repeat thyroid function tests revealed a free $T_{4}$ of $65 \mathrm{pmol} / 1$ (normal 11-26) with an undetectable TSH. There was no evidence of hydatidiform mole or choriocarcinoma on a pelvic ultrasound scan. Thyroid antibodies were negative. The hyperemesis was managed conservatively and 10 days later the free $T_{4}$ had fallen to $35 \mathrm{pmol} / \mathrm{l}$. These and subsequent results are shown in the figure. Measurements of total $T_{3}$ on all samples were normal. Return of the free $T_{4}$ to normal was associated with a rise in TSH to within the normal range.

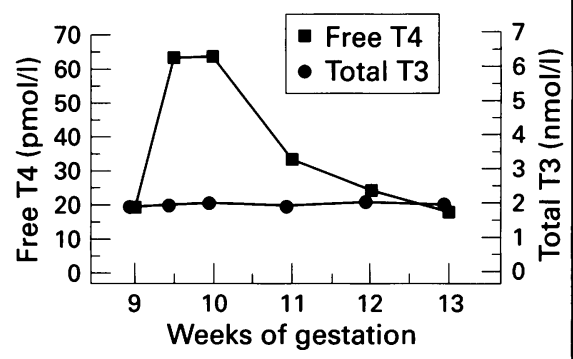

Figure Levels of free $T_{4}$ and total $T_{3}$ vs weeks of gestation

Box 4

\section{'Genuine' vs 'gestational' thyrotoxicosis}

- clinical evidence of autoimmune aetiology suggests Graves' disease (dysthyroid eye signs, pre-tibial myxoedema, thyroid acropachy)

- antithyroid antibodies

- red cell zinc concentration ties of thyroid function tests in the absence of intrinsic thyroid disease. Moreover, the extent of the disturbance (increase in free $\mathrm{T}_{4}$ and suppression of $\mathrm{TSH}$ ) correlates with the severity of the vomiting. ${ }^{12}$ It has been thought that the high levels of hCG often associated with profound vomiting are responsible for the frequency of abnormal thyroid function tests seen in these women. However, it has been shown that sera from women with recent terminations (and therefore with low levels of hCG) may stimulate thyroid cells to secrete $T_{4}$ and $T_{3}$ in vitro. ${ }^{13}$ The confusion is likely to be due to the fact that hCG is a heterogenous glycoprotein, with different patterns of sialylation during different periods of pregnancy. Recent evidence suggests that asialo isomers of $\beta$-hCG have the greatest thyroid-stimulating activity and that these isomers are present in higher titres in patients with severe vomiting in early pregnancy. ${ }^{14}$

A frequent clinical problem, therefore, is the interpretation and management of thyroid function tests carried out on women admitted to hospital with vomiting in early pregnancy. Is the patient truly 'thyrotoxic' (with vomiting as the presenting symptom), or does she simply have severe vomiting in early pregnancy with the frequently associated hyperthyroxinaemia (often referred to as 'gestational thyrotoxicosis')? Clinically, the two may be difficult to distinguish, although the presence of dysthyroid eye disease, pre-tibial myxoedema or thyroid acropachy suggest Graves' disease. The presence of antithyroid antibodies also supports a diagnosis of Graves' disease, although a low titre may be accounted for by the 'immunosuppressed' state of pregnancy. Measurement of intraerythrocytic zinc has been suggested as a discriminatory test. ${ }^{15}$ Thyrotoxicosis inhibits the formation of carbonic anhydrase, a zinc metallo-enzyme, over a period of several weeks. Low levels of erythrocytic zinc are therefore seen with 'genuine' thyrotoxicosis whereas levels are normal in hyperemesis gravidarum, where the disturbance of thyroid function takes place over a shorter period.

Perinatal outcome in gestational thyrotoxicosis appears to be no different to pregnancies not complicated by severe vomiting, so in most cases it is possible to pursue conservative management rather than commence antithyroid medication. Where vomiting and hyperthyroxinaemia persist beyond 20 weeks gestation, treatment with antithyroid medication is probably justified.

\section{FOETAL AND NEONATAL THYROTOXICOSIS}

It is important to remember that, aside from the effects of hyperthyroxinaemia, maternal Graves' disease and Hashimoto's thyroiditis may affect the foetus due to placental transfer of antithyroid antibodies. This is unusual and does not necessarily correlate with the presence of active disease in the mother. The earliest sign of foetal thyrotoxicosis is a tachycardia $>160$ beats $/ \mathrm{min}$ and, if uncorrected, serious effects on growth and cardiovascular function may follow. In some cases, transient neonatal thyrotoxicosis follows the post-partum decline of the effect of antithyroid medication. Careful obstetric supervision and specialist supervision of antithyroid medication are important both in utero and post-partum. The question as to whether hyperthyroxinaemia early in life may be associated with subsequent hyperactivity and behavioural disturbances remains controversial. ${ }^{16}{ }^{17}$

\section{TREATMENT}

The mainstay of the management of thyrotoxicosis in pregnancy is the use of thionamide drugs (carbimazole and propylthiouracil), both of which block organification of iodide and iodination of tyrosine. Both drugs cross the 
placenta, carbimazole (or rather its active metabolite methimazole) more freely than propylthiouracil, although clinically there appears to be little advantage of one over the other. Previous concerns about the possible association of aplasia cutis (a condition characterised by patches of absent skin, particularly on the scalp) have not been confirmed. Side-effects of thionamide therapy (rash, nausea and agranulocytosis) are no more or less common in pregnancy. Breast feeding is possible with both drugs used in low doses (eg, carbimazole 5-15 mg daily), but if higher doses are required then it is essential to monitor the baby's thyroid function. ${ }^{18} \beta$-Blockers such as propranolol are commonly used for symptomatic relief in non-pregnant thyrotoxic patients, but concern about growth retardation and postnatal hypoglycaemia ${ }^{19}$ limit their use to pregnant patients with severe thyrotoxicosis. In resistant cases, or where poor compliance prevents satisfactory control, thyroidectomy (either total or subtotal) may be indicated. Such a decision represents a balance between the risks of anaesthesia and surgery against the effects of uncontrolled thyrotoxicosis and should only be made after careful discussion between patient, obstetrician, physician and surgeon. Radioactive iodine is absolutely contraindicated in pregnancy.

\section{Post-partum thyroid disease}

It is important to appreciate that post-partum thyroid disease falls into two categories: pre-existing thyroid disease, the clinical course of which is modified by the pregnancy, and a distinct post-partum thyroiditis that characteristically passes through thyrotoxic and hypothyroid phases, culminating in euthyroidism.

The clinical course of Graves' disease and Hashimoto's thyroiditis are often ameliorated by pregnancy, in keeping with the concept that the maternal immune system is somehow 'blunted' in order to accommodate the placenta. In the post-partum period there is often a 'rebound' exacerbation, although a close correlation between the severity of thyroid disturbance and titres of antithyroid antibodies has been difficult to demonstrate.

There exists a separate group of patients, also antithyroid-antibody positive, who undergo significant changes in thyroid function post-partum, in the absence of documented abnormalities of thyroid function during pregnancy. ${ }^{20}$ Characteristically, a period of low grade (often subclinical) thyrotoxicosis approximately 3 months post-partum is followed by mild hypothyroidism and, within a year or so, euthyroidism. Symptoms are generally mild, although in a small number of women the symptoms of depression and irritability may be particularly troublesome and require temporary thyroxine replacement therapy. ${ }^{21}$ Uptake of radioiodine during the toxic phase is reduced and, where there is diagnostic doubt, this helps distinguish post-partum thyroiditis from Graves' disease, although breast feeding must be stopped.

The question as to whether post-partum thyroiditis is a genuinely separate clinical entity or simply part of a spectrum of autoimmune thyroid disease (with pregnancy acting as a trigger for a process that would have occurred anyway) is not clear. There is evidence that a significant proportion of women with post-partum thyroiditis become permanently hypothyroid in subsequent years. ${ }^{22}$

1 Ain KB, Mori Y, Refetoff S. Reduced clearance rate of thyroxine-binding globulin (TBG) with increased sialylation: a mechanism for estrogeninduced elevation of serum TBG concentration. f Clin Endocrinol Metab 1987;65:689-96.

2 Burrow GN. Maternal and fetal thyroid function. N Engl ₹ Med 1994;331:1072-7.

3 Crooks J, Aboul-Khair SA, Turnbull AC Hytten FE. The incidence of goitre during pregnancy. Lancet 1964;ii:334-6.

4 Nelson M Wickus GG, Caplan RH, Begui EA

Thyroid gland size in pregnancy: an ultrasound Thyroid gland size in pregnancy: an ultrasound
and clinical study. $₹$ Reprod Med 1987;32:888and

5 Vulsma T, Gons MH, De Vijlder JM. Maternalfetal transfer of thyroxine in congenital hypothyroidism due to a total organification defect of thyroid agenesis. $N$ Engl $\mathcal{F}$ Med 1989;321:13-6.

6 Parker RH, Bierwaltes WH, Elzinga KF, et al Thyroid antibodies during pregnancy and in the newborn. $\mathcal{F}$ Clin Endocrinol Metab 1961;21:7926.

7 Mandel SJ, Larsen PR, Seely EW, Brent GA. Increased need for thyroxine during pregnancy in women with primary hypothyroidism. $N$ Engl in women with primary

8 Greenman GW, Gabrielson MA, Howard-

Flanders I, et al. Thyroid dysfunction in pregnancy, fetal loss and follow-up evaluation of surviving infants. $N$ Engl $f$ Med 1962;267:4269.
9 Davis LE, Lucas MJ, Hankins GDV, Roark ML, Cunningham FG. Thyrotoxicosis complicating pregnancy. Am $\mathcal{F}$ Obstet Gynecol 1989;167:6370 .

10 Burrow GN. The Management of thyrotoxicosis in pregnancy. $N$ Engl $\mathcal{f}$ Med (1985);313:562-5.

11 Hershman JM, Higgins HP. Hydatidiform mole-a cause of clinical hyperthyroidism. NEng f Med 1971;284:573-7.

12 Goodwin T, Montoro M, Mestman J, Pekary A, Hershman J. The role of chorionic gonadotropin in transient hyperthyroidism in hyperemesi gravidarum. F Clin Endocrinol Metab 1992;75 1333-7.

13 Kennedy RL, Darne J, Cohn M, Price A, Davies $R$, Blumsohn A, Griffiths H. Human chorionic gonadotropin (hCG) may not be responsible for the thyroid-simulating activity in normal pregthe thyroid-simulating activity in normal pregnancy se

14 Tsuruta E, Tada H, Tamaki H, et al. Pathogenic role of asialo human chorionic gonadotropin in gestational thyrotoxicosis. $\mathcal{f}$ Clin Endocrinol Metab 1995;80:350-5.

15 Lao TT, Chin RK, Swaminathan R, Panesar NS, Cockram CS. Erythrocytic zinc in differential diagnosis of hyperthyroidism in pregnancy: a preliminary report. BMF (Clin Res Edn) 1987 ; 294:1064-5.
16 Vaccari A. Teratogenic mechanisms of dysthyroidism in the central nervous system. Prog Brain Res 1988;73:71-86.

17 Morreal de Escobar G, Obregaon MJ, Escobar del Rey F. Fetal and maternal thyroid hormones. Horm Res 1987;26:12-27.

18 Vanderpump MPJ, Ahlquist JAO, Franklyn JA, Clayton RN. Consensus statement for good practice and audit measures in the management of hypothyroidism and hyperthyroidism. $B M Y$ of hypothyroidism

19 Pruyn SC, Phelan JP, Buchanan GC. Long term propranolol therapy in pregnancy: maternal and fetal outcome. Am $\mathcal{F}$ Obstet Gynecol 1979;135:485-9.

20 Hall R. Pregnancy and autoimmune endocrine disease. Balliere's Clin Endocrinol Metab 1995;9: 137-55.

21 Lazarus JH, Hall R, Othman S, et al. The clinical spectrum of post-partum thyroid disease. $Q$ f Med 1996;89:429-35.

22 Othaman S, Philips DIW, Parkes AB, Richards CJ, Harris B, Lazarus JH. A long-term follow-up of post-partum thyroiditis. Clin Endo crinol 1990;32:559-64. 